\title{
LIPE C-60G influences the effects of physical activity on body fat and plasma lipid concentrations: The Quebec Family Study
}

\author{
Christophe Garenc, 1,2 Marie-Claude Vohl, 2,3 Claude Bouchard ${ }^{4}$ and Louis Pérusse $2,5^{*}$ \\ 'Département de Médecine, Université Laval, Québec, QC, G1K 7P4 Canada \\ ${ }^{2}$ Centre de recherche sur les maladies lipidiques (CRML), Centre de Recherche du Centre Hospitalier de l'Université Laval du \\ CHUQ, Université Laval, Québec, QC, G1V 4G2 Canada \\ ${ }^{3}$ Département des sciences des Aliments etde Nutrition, Université Laval, Québec, QC, G1K 7P4 Canada \\ ${ }^{4}$ Pennington Biomedical Research Center, 6400 Perkins Road, Baton Rouge, LA, 70808 USA \\ ${ }^{5}$ Division de Kinésiologie, Département de médecine sociale et préventive, Université Laval, Québec, QC, G1K 7P4 Canada \\ *Correspondence to: Tel: +1 418656 7831; Fax: +1 418656 3044; E-mail: louis.perusse@kin.msp.ulaval.ca
}

Date received (in revised form): 9th July 2008

\begin{abstract}
A large body of evidence suggests that the environment plays an important role in the development of obesity. The hormone-sensitive lipase (encoded by the LIPE gene) is an intracellular enzyme that mobilises fat stores in a hormone-stimulated manner. The aim of the present study was to determine the effects of the LIPE C-60G polymorphism on body fat and plasma lipid and lipoprotein concentrations, and to test for its interaction with physical activity. The LIPE C-60G polymorphism was genotyped in 862 subjects from the Quebec Family Study. Body mass index (BMI), fat mass, percentage body fat, abdominal fat areas assessed by computed tomography, and detailed fasting plasma lipid and lipoprotein profiles were measured. Levels of physical activity were estimated using a three-day diary, and a moderate to strenuous physical activity score was retained for this study. The main effects of the LIPE C-60G polymorphism, physical activity and their interaction were determined by regression analyses separately in men and women using the MIXED model procedure. In men, we observed significant gene-physical activity interactions for BMI $(p=0.006)$, fat mass $(p=0.04)$, abdominal visceral fat area $(p=$ $0.005)$ and plasma cholesterol $(C)$ high-density lipoprotein cholesterol (HDL-C) ratio $(p=0.003)$. A high level of physical activity was associated with reduced adiposity and a lower plasma-C/HDL-C ratio, but only in noncarriers of the genetic variant (G-60 allele). In women, no evidence of a gene by physical activity interaction was observed, except for subcutaneous abdominal fat $(p=0.05)$. These results suggest that the associations between physical activity and body fat and plasma lipoprotein/lipid concentrations in men are dependent on the LIPE C-60G polymorphism, and highlight the importance of taking into account the role of gene-physical activity interactions in candidate gene studies of obesity and obesity-related traits.
\end{abstract}

Keywords: hormone-sensitive lipase, body fat, plasma lipid and lipoprotein levels, gene-environment interaction

\section{Introduction}

The hormone-sensitive lipase (HSL) plays an important role in triacylglycerol (the major fuel stored in adipose tissue) catabolism via a hormone-stimulated lipolysis process. ${ }^{1}$ Its activity is regulated by catecholamines that induce adenylate 
cyclase and cyclic adenosine monophosphate (cAMP) formation, which, in turn, activates protein kinase A and a cAMP-mediated phosphorylation of a single serine residue on HSL. Insulin exerts its hypolipidaemic effect by activating a cAMP phosphodiesterase, leading to lower intracellular cAMP concentrations, thereby inhibiting cAMP-dependent protein kinase phosphorylation. ${ }^{2,3}$ Thus, in adipose tissue, lipid mobilisation depends on the balance between the stimulatory and inhibitory pathways of HSL activation. ${ }^{2,45}$ During exercise, lipid mobilisation from adipose tissue is mainly stimulated by increased catecholamine production, leading to enhanced $\beta$-adrenoceptor-mediated stimulation of lipolysis. ${ }^{6}$ In skeletal muscle, it has been shown that HSL activity is increased at the onset of low to moderate intensity exercise, and is essential for intramuscular triacylglycerol mobilisation, but does not seem to be the only factor responsible for their mobilisation. $^{7}$

The hormone-sensitive lipase gene (LIPE) is located on chromosome 19 (19q13.2, 52.1 centimorgans $)^{8}$ in a region previously shown to be linked to plasma low-density lipoprotein cholesterol (LDL-C) concentrations, ${ }^{9}$ plasma triglyceride (TG) levels and adiposity ${ }^{10}$ and plasma TG concentrations in families suffering from type 2 diabetes. $^{11}$ A LIPE C-60G point mutation located in front of the first exon coding for the protein with triacylglycerol lipase activity $^{12}$ has been associated with body composition $^{13}$ and waist circumference in normal-weight subjects. ${ }^{14}$ The rare G-60 allele leads to a 40 per cent reduction in transcriptional activity in vitro, ${ }^{12,14}$ and has been associated with higher insulin sensitivity in women ${ }^{15}$ but higher LDL-C in men. ${ }^{15,16}$ It has been proposed that the LIPE G-60 allele has opposite effects on glucose homeostasis, protecting against insulin resistance in healthy young men ${ }^{17}$ but increasing fasting glucose levels in non-drinker men only. ${ }^{16}$ These observations suggest that the effect of the LIPE C-60G polymorphism on plasma lipids are gender specific and may vary according to lifestyle habits. A meta-analysis of randomised controlled trials suggested that low-intensity physical activity, such as walking, reduces LDL-C and the total-cholesterol/high-density lipoprotein cholesterol
(HDL-C) ratio independently of changes in body composition. ${ }^{18}$ Some reports have shown the importance of gene-physical activity interactions on health-related phenotypes. ${ }^{19}$

We hypothesised that the effects of the LIPE C-60G polymorphism on body fat and plasma lipid and lipoprotein concentrations are dependent on physical activity levels. The aim of the present study was to investigate the effects of the LIPE C-60G by physical activity interactions on body composition and plasma lipid and lipoprotein concentrations in subjects participating in the Quebec Family Study (QFS).

\section{Materials and methods}

\section{Subjects}

The present study was undertaken using data from the QFS, which involved Caucasian families of French descent living within an $80 \mathrm{~km}$ radius of Quebec, as described in detail previously. ${ }^{20}$ After exclusion of subjects taking lipid-lowering drugs (statins, fibrates, nicotinic acid), anthropometric information, as well as plasma lipid and lipoprotein concentrations, were available for 862 subjects from 222 nuclear families. The Institutional Review Board of Laval University approved the study protocol, and informed written consent was obtained from each participant.

\section{Anthropometric and abdominal fat area measurements}

Anthropometric variables included body mass index (BMI) - computed as weight $(\mathrm{kg}) /$ height (m) - and percentage body fat (per cent) estimated from body density measurements obtained using the hydrostatic weighing technique $^{21}$ and derived from the Siri equation. ${ }^{22}$ Fat mass $(\mathrm{kg})$ was calculated from percentage body fat and body weight. Abdominal visceral and total abdominal fat areas were assessed using computed tomography between the fourth and fifth lumbar (L4-L5) vertebrae, as described previously. ${ }^{23}$ The abdominal subcutaneous fat area was obtained by calculating the difference between total and abdominal visceral fat areas. 


\section{Plasma lipid and lipoprotein measurements}

Blood samples were collected in the morning, after a 12-hour overnight fast, from the antecubital vein into vacutainer tubes containing ethylene diamine tetra-acetic acid (EDTA). Blood drawing and determination of plasma lipid and lipoprotein concentrations have been detailed previously. ${ }^{24}$ Briefly, cholesterol $^{25}$ and $\mathrm{TG}^{26}$ concentrations were determined enzymatically using a Technicon RA-500 automated analyser (Bayer, Tarrytown, NY, USA). The plasma very-low-density lipoprotein (VLDL) (density $<1.006 \mathrm{~g} / \mathrm{ml}$ ) fraction was isolated by ultracentrifugation, whereas the HDL fraction was obtained after precipitation of LDL in the infranatant (density $>1.006 \mathrm{~g} / \mathrm{ml}$ ) with heparin and $\mathrm{MnCl}_{2}^{27}$. TG and cholesterol levels in the infranatant fraction were measured before and after the precipitation step. Apolipoprotein B (apoB) and apolipoprotein A1 (apoA1) concentrations were measured according to the rocket immunoelectrophoretic method of Laurell, $^{28}$ as previously described, ${ }^{29}$ in the total plasma, LDL (apoB) and HDL (apoA1) fractions. VLDL-apoB content was derived from the difference between plasma apoB and LDL-apoB concentrations.

\section{Physical activity level}

Physical activity level was assessed using a three-day (two week days and one weekend day) activity diary, as described previously. ${ }^{30}$ Briefly, each day of the diary was divided into 96 periods of 15 minutes, and for each period subjects were instructed to record their dominant activity, using a list of activities categorised in order of increased energy expenditure (metabolic equivalents), using scores ranging from 1 (resting energy expenditure) to 9 (high-intensity exercise).$^{30}$ In order to assess participation in moderate to strenuous physical activity, we only focused on activities which scored between 5 and 9. The number of 15-minute periods for each of the categories between 5 and 9 was firstly summed over each day and weighted by its own category number. A physical activity score, computed as the average sum of scores between 5 and 9 over three days, was then obtained and used as an indicator of participation in moderate to strenuous physical activities. ${ }^{31}$

\section{Molecular analysis}

A mini-sequencing assay was performed in a final volume of $16 \mu \mathrm{l}$ containing $1.56 \mu \mathrm{M}$ each of dGTP, ddATP, ddCTP and ddTTP (Amersham Pharmacia Biotech Inc., Baie d'Urfé, QC, Canada), 3.125 nM of forward (5'-GGACTCCTGGGTTCTAAG-3'), reverse (5'-ATTCCCGTCTCTCAGCTG-3') and IRDye tag mini-sequencing $\left(5^{\prime}-\right.$ TTTTTTTTTCC TTCCACTCTAGGGCTGAT-3') primers (LICOR, Lincoln, NE, USA); $0.3 \mathrm{U}$ of ThermoSequenase (Amersham Pharmacia Biotech Inc.) and 0.6x buffer (10x: $260 \mathrm{nM}$ Tris- $\mathrm{HCl}$ and $65 \mathrm{mM} \mathrm{MgCl}_{2}$ at $\mathrm{pH}$ 9.5). Following a two-minute denaturation step at $95^{\circ} \mathrm{C}, 30$ polymerase chain reaction amplification cycles were performed as follows: denaturation at $95^{\circ} \mathrm{C}$ for 10 seconds, annealing at $57^{\circ} \mathrm{C}$ for 30 seconds and extension at $72^{\circ} \mathrm{C}$ for 5 seconds. The amplicon was 308 base pairs (bp) long. Detection was performed using a LICOR automated sequencer, model 4200.

\section{Statistical analysis}

All statistical analyses were performed using SAS 8.12 software. ${ }^{32}$ Prior to adjustment, the normality of the distribution of each variable was tested and variables not normally distributed were transformed. This was the case for plasma TG and VLDL-TG ( $\log _{10}$ transformation) and physical activity score (square root transformation). Deviation from Hardy-Weinberg equilibrium for the LIPE C-60G polymorphism was assessed using a $\chi^{2}$ test (Table 1$)$.

Association analyses and tests of interaction were performed on residual scores computed for all subjects using stepwise regression procedures. Each phenotype was regressed on age, separately within each of six age-by-sex groups $(<30, \geq 30$ to $<50$ and $\geq 50$ years), keeping only equation terms that were significant at the 5 per cent level. Abdominal visceral fat and plasma lipid and lipoprotein phenotypes were further adjusted for the effect of fat mass. For adjustment purposes, the outliers, defined as those beyond \pm 3 SD for each group, were temporally set aside. The regression parameters were then used to calculate the residuals for all subjects, including the outliers. Regression analyses performed separately in men and women were then 
Table I. Genotype and allele frequencies for LIPE C-60G polymorphism in unrelated subjects from the Quebec Family Study

\begin{tabular}{|c|c|c|c|c|c|c|c|c|}
\hline Gene & Polymorphism & Genotype & $\begin{array}{l}\text { Genotype } \\
\text { frequency }\end{array}$ & $\begin{array}{c}\text { Number } \\
\text { of } \\
\text { subjects }\end{array}$ & Allele & $\begin{array}{l}\text { Allele } \\
\text { frequency }\end{array}$ & $\begin{array}{l}95 \% \\
\mathrm{Cl}^{\mathrm{a}}\end{array}$ & $\begin{array}{l}\text { Deviation } \\
\text { from } \mathrm{H}-\mathrm{W}\end{array}$ \\
\hline & & $C-60 C$ & 90.21 & 350 & & & & \\
\hline \multirow[t]{2}{*}{ LIPE } & \multirow[t]{2}{*}{ C-60G } & C-60G & 9.54 & 37 & $\begin{array}{l}-60 C \\
-60 G\end{array}$ & $\begin{array}{l}0.9497 \\
0.0503\end{array}$ & 0.0154 & $\begin{array}{r}\chi^{2}=0.0004 \\
\text { df }=1 \\
p=0.98\end{array}$ \\
\hline & & G-60G & 0.26 & I & & & & \\
\hline
\end{tabular}

Abbreviations: $\mathrm{H}-\mathrm{W}$, Hardy-Weinberg equilibrium; $\mathrm{Cl}$, confidence interval

${ }^{a} 95$ per cent $\mathrm{Cl}$ for allele frequencies were computed as I.96SQRT(pq/n), where $\mathrm{p}$ is the most common allele frequency, $q$ is the rare allele frequency and $\mathrm{n}$ the number of alleles.

used to test the effects of the LIPE C-60G polymorphism, physical activity and gene-physical activity interaction on the adjusted phenotypes (residuals). The MIXED procedure was used for carrying out these regression analyses because it provides flexibility for modelling the covariance in the data resulting from the fact that the experimental units (in this case the subjects) can be grouped into clusters (the families) and that data from a common cluster are correlated. By using this procedure, it is thus possible to take into account the non-independence of family members in the association analyses. Variables showing significant evidence of gene-physical activity interaction were then tested for association with the LIPE C-60G polymorphism separately in men and women, using the same MIXED model procedure, but this time the association analyses were performed separately in each of the four physical activity-genotype groups (low and high physical activity groups based on the sex-specific median values of physical activity score and carriers versus non-carriers of the G-60 allele) using age-adjusted data. Least square means were extracted and tested for differences between the groups using $t$-tests (Figure 1).

\section{Results}

\section{Body fat and plasma lipid and lipoprotein concentrations}

Body fat and physical activity variables are summarised in Table 2. No differences in age or in BMI were observed between men and women from both generations. Fathers, mothers, sons and daughters were, on average, within the overweight range $\left(25 \mathrm{~kg} / \mathrm{m}^{2}<\right.$ BMI $\left.<30 \mathrm{~kg} / \mathrm{m}^{2}\right)$. Women were characterised by having significantly more abdominal subcutaneous fat (mothers: +50 per cent; daughters: +56 per cent), while men exhibited more body fat accumulation in the abdominal visceral region (fathers: +35 per cent; sons: +21 per cent) than their gender counterparts. Daughters exhibited a significantly lower physical activity score ( -39 per cent) than sons, while fathers and mothers did not exhibit any difference.

Plasma lipid and lipoprotein concentrations are summarised in Table 3. In both generations, no gender differences were observed in plasma cholesterol levels; however, males of both generations exhibited significantly higher VLDL-TG concentrations (fathers: +28 per cent; sons: +28 per cent) than women. Men had higher apoB concentrations $(+14$ per cent only in the older generation) in this lipid fraction. As compared to mothers, higher LDL-C (+8 per cent) and LDL-apoB $(+11$ per cent) concentrations were observed in fathers, but this was not the case in the younger generation (no gender difference). Males of both generations exhibited significantly lower HDL-C concentrations (fathers: -22 per cent; sons: -12 per cent) than females. Finally, men exhibited significantly higher plasma cholesterol/HDL-C ratios $(+31$ per cent in fathers and +13 per cent in sons) than women, suggesting a greater cardiovascular risk in men. 

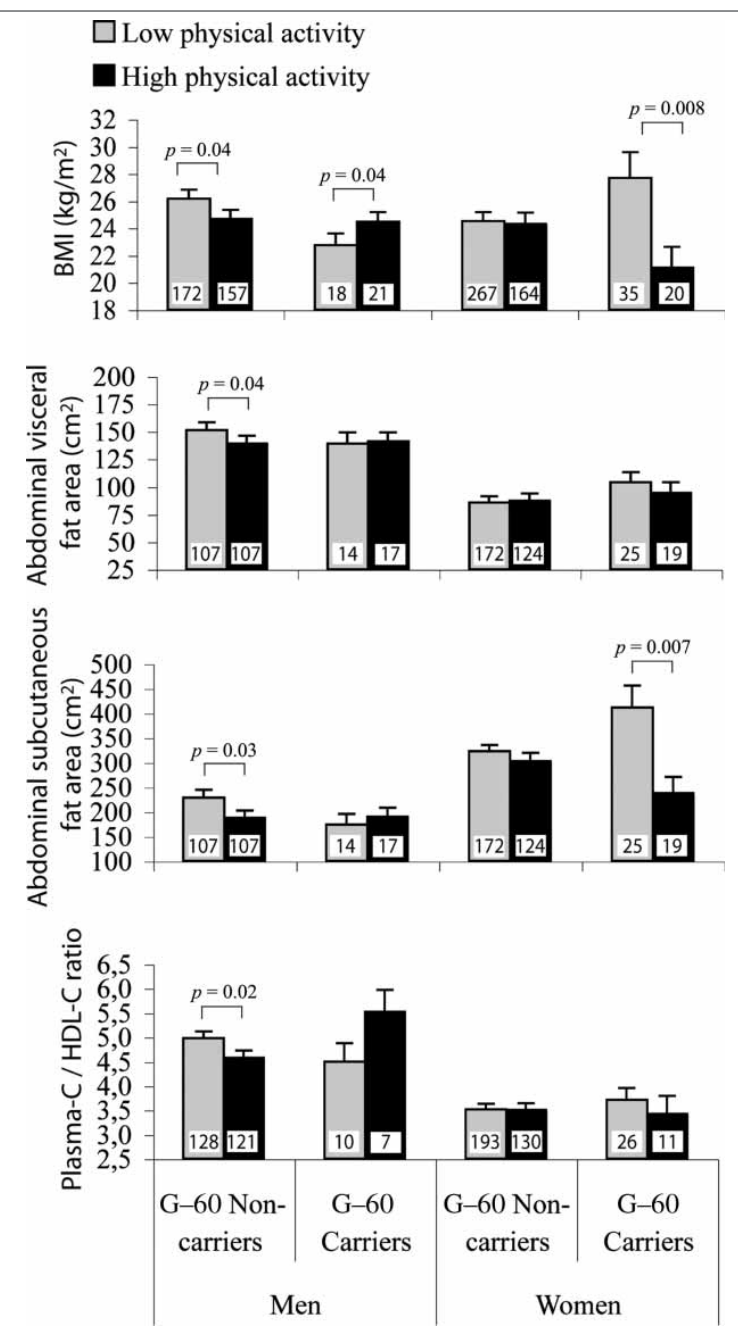

Figure I. LIPE (C-60G)-physical activity score interaction on body mass index (BMI), abdominal visceral fat area, abdominal subcutaneous fat area and plasma cholesterol (C)/high-density lipoprotein cholesterol (HDL-C) ratio in subjects from the Quebec Family Study with low and high physical activity scores (cut-off defined by the median). Numbers are number of subjects in each group.

\section{Allelic frequency}

Allele and genotype frequencies of LIPE C-60G calculated using parental data alone are presented in Table 1. The genotype frequencies did not deviate from the Hardy-Weinberg expectation $(p=0.98)$. No allelic differences were found between males and females $\left(\chi^{2}=3.08, p=0.21\right)$ or between obese and non-obese subjects (BMI cut off $=$ $\left.30 \mathrm{~kg} / \mathrm{m}^{2}\right)\left(\chi^{2}=0.52, p=0.77\right)$.

\section{Association between LIPE C-60G, body fat and plasma lipid and lipoprotein concentrations}

The results of association analyses are presented in Tables 4 and 5 for men and women, respectively. These Tables present the $p$-values for the main effects of the gene and physical activity level, as well as for the gene-physical activity interaction. The Tables also present the regression coefficients for interaction between physical activity and LIPE genotypes (C-60C and G-carriers), as well as their corresponding $p$-values.

Except for BMI in men $(p=0.006)$, no evidence of association was observed between the LIPE C-60G polymorphism and adiposity or lipid and lipoprotein phenotypes in both men and women. In men, physical activity had a significant effect on fat mass $(p=0.02)$, percentage body fat $(p=0.04)$ and on LDL-C/LDL-apoB $(p<0.0001)$ and HDL-C/ apoA1 $(p<0.0001)$ ratios. In women, physical activity had a significant effect on BMI $(p=0.02)$, fat mass $(p=0.04)$, percentage body fat $(p=0.01)$, abdominal subcutaneous fat $(p=0.002)$ and abdominal total fat $(p=0.003)$ areas, but no effect on lipid and lipoprotein phenotypes.

In men, we observed significant LIPE C-60Gphysical activity interactions on BMI $(p=0.006)$, fat mass $(p=0.04)$, abdominal visceral fat area $(p=$ $0.005)$, and on HDL-C $(p=0.04)$, total apoB ( $p=$ $0.01)$ and LDL-apoB $(p=0.02)$ concentrations, as well as on plasma cholesterol/HDL-C $(p=0.003)$, LDL-C/LDL-apoB $(p<0.0001)$ and HDL-C/ HDL-apoA1 $(p=0.004)$ ratios (Table 4$)$. As shown in Figure 1, in non-carriers of the LIPE G-60 variant, a high physical activity level is associated with lower BMI (low physical activity: $26.1 \pm$ $0.7 \mathrm{~kg} / \mathrm{m}^{2}$; high physical activity: $24.7 \pm 0.7 \mathrm{~kg} / \mathrm{m}^{2}$; $p=0.04$ ), abdominal visceral fat (low physical activity: $151.1 \pm 7.3 \mathrm{~cm}^{2}$; high physical activity: $\left.138.9 \pm 7.2 \mathrm{~cm}^{2} ; p=0.04\right)$ and abdominal subcutaneous fat (low physical activity: $228.8 \pm 15.8 \mathrm{~cm}^{2}$; high physical activity: $187.9 \pm 14.8 \mathrm{~cm}^{2} ; p=0.03$ ). Such a beneficial effect of physical activity is not seen in carriers of the G-60 allele. Similarly, the beneficial effects of physical activity on the lipid profile was observed only in non-carriers of the variant, 
Table 2. Body fat and physical activity phenotypes in subjects of the Quebec Family Study

\begin{tabular}{|c|c|c|c|c|}
\hline Phenotype & Fathers & Mothers & Sons & Daughters \\
\hline Age (years) & $55.5 \pm 10.3(165)$ & $53.8 \pm 12.2(231)$ & $26.6 \pm 9.6(206)$ & $28.0 \pm 10.5(260)$ \\
\hline \multicolumn{5}{|l|}{ Body fat } \\
\hline $\mathrm{BMI}\left(\mathrm{kg} / \mathrm{cm}^{2}\right)$ & $28.5 \pm 5.9(163)$ & $28.4 \pm 7.9(228)$ & $26.3 \pm 7.0(205)$ & $26.8 \pm 8.8(258)$ \\
\hline Fat mass $(\mathrm{kg})$ & $23.0 \pm 10.7(122)$ & $27.1 \pm 14.2(156) * *$ & $18.0 \pm 15.1(182)$ & $22.4 \pm 15.3(235) * *$ \\
\hline $\begin{array}{l}\text { Percentage } \\
\text { body fat (\%) }\end{array}$ & $26.6 \pm 7.0(122)$ & $35.6 \pm 8.9(156) * * *$ & $20.2 \pm 10.0(182)$ & $29.5 \pm 10.6(235) * * *$ \\
\hline $\begin{array}{l}\text { Abdominal } \\
\text { visceral fat } \\
\left(\mathrm{cm}^{2}\right)\end{array}$ & $173.5 \pm 86.2(108)$ & $128.6 \pm 71.0(156) * * *$ & $90.9 \pm 66.0(137)$ & $75.3 \pm 56.8(184) *$ \\
\hline $\begin{array}{l}\text { Abdominal } \\
\text { subcutaneous } \\
\text { fat }\left(\mathrm{cm}^{2}\right)\end{array}$ & $237.8 \pm 108.9(108)$ & $357.43 \pm 168.0(156) * * *$ & $209.7 \pm 160.7(137)$ & $327.2 \pm 197.6(184) * * *$ \\
\hline $\begin{array}{l}\text { Abdominal total } \\
\text { fat }\left(\mathrm{cm}^{2}\right)\end{array}$ & $411.4 \pm 173.1(108)$ & $485.9 \pm 225.5(156) * *$ & $300.6 \pm 214.5(137)$ & $402.5 \pm 241.3(184) * * *$ \\
\hline $\begin{array}{l}\text { Physical } \\
\text { activity score }\end{array}$ & $85.4 \pm 68.8(137)$ & $69.4 \pm 46.4(185)$ & $77.0 \pm 62.2(184)$ & $55.5 \pm 46.8(228) * * *$ \\
\hline
\end{tabular}

who exhibited reduced LDL-apoB values (low physical activity: $0.91 \pm 0.02 \mathrm{~g} / \mathrm{L}$; high physical activity: $0.85 \pm 0.02 \mathrm{~g} / \mathrm{L} ; p=0.02)$, as well as a lower plasma cholesterol/HDL-C ratio (low physical activity: $4.98 \pm 0.14$; high physical activity: $4.57 \pm 0.15 ; p=$ 0.02; Figure 1). In LIPE G-60 carriers, high level physical activity was associated with a higher BMI value (low physical activity: $22.7 \pm 0.9 \mathrm{~kg} / \mathrm{m}^{2}$; high physical activity: $\left.24.4 \pm 0.7 \mathrm{~kg} / \mathrm{m}^{2} ; p=0.04\right)$.

In women, a significant LIPE C-60G-physical activity interaction was observed for abdominal subcutaneous fat area $(p=0.05)$ (Table 5$)$. As shown in Figure 1, and unlike the results found in men, the beneficial effect of physical activity on adiposity in women was observed in carriers of the G-60 allele. Indeed, in women, a high physical activity level was associated with a lower BMI (low physical activity: $27.7 \pm 1.9 \mathrm{~kg} / \mathrm{m}^{2}$; high physical activity: $21.1 \pm 1.5 \mathrm{~kg} / \mathrm{m}^{2} ; \quad p=0.008 ; \quad$ LIPE $\quad$ C-60Gphysical activity interactions term: $p=0.09$ ) and abdominal subcutaneous fat area (low physical activity:
$411.3 \pm 43.8 \mathrm{~cm}^{2}$; high physical activity: $237.1 \pm$ $\left.33.1 \mathrm{~cm}^{2} ; p=0.007\right)$ in the $\mathrm{G}-60$ carriers.

\section{Discussion}

In the present study, we showed that the effects of physical activity on body fat and plasma lipid levels were influenced by LIPE C-60G polymorphism. In our study sample, the frequency of the LIPE G-60 allele (0.0503) was between the frequencies reported in the Baltic region of Europe (0.037) and southern Europe (0.087). ${ }^{17}$ It was also very close to the frequency observed in Caucasians of the HERITAGE Family Study (0.07). ${ }^{13}$

HSL is responsible for triglyceride mobilisation and is largely expressed in white adipose tissue, skeletal muscle and pancreatic $\beta$-cells ${ }^{3}$ but does not appear to be the only enzyme responsible for fat mobilisation in adipose tissue. The role of HSL (as the rate-limiting enzyme for triglyceride mobilisation) has been questioned, since the 
Table 3. Plasma lipid and lipoprotein profile parameters in subjects of the Quebec Family Study

\begin{tabular}{|c|c|c|c|c|}
\hline Phenotype & Fathers & Mothers & Sons & Daughters \\
\hline \multicolumn{5}{|l|}{ Cholesterol } \\
\hline Plasma (mmol/L) & $5.33 \pm 0.88(111)$ & $5.18 \pm 0.98(156)$ & $4.44 \pm 0.90(155)$ & $4.44 \pm 0.84(204)$ \\
\hline LDL (mmol/L) & $3.68 \pm 0.79(111)$ & $3.42 \pm 0.85(156) * *$ & $2.94 \pm 0.79(155)$ & $2.89 \pm 0.78(204)$ \\
\hline $\mathrm{HDL}(\mathrm{mmol} / \mathrm{L})$ & $0.97 \pm 0.22(111)$ & $1.24 \pm 0.31(156) * * *$ & $1.02 \pm 0.22(155)$ & $1.16 \pm 0.26(204) * * *$ \\
\hline \multicolumn{5}{|l|}{ Triglyceride } \\
\hline Plasma (mmol/L) & $1.83 \pm 1.00(1 \mathrm{II})$ & $1.57 \pm 0.77(156) *$ & $1.39 \pm 0.72(155)$ & $1.22 \pm 0.56(204)$ \\
\hline VLDL (mmol/L) & $1.24 \pm 0.82(\mathrm{III})$ & $0.97 \pm 0.65(156) * *$ & $0.91 \pm 0.60(155)$ & $0.71 \pm 0.47(204) * *$ \\
\hline \multicolumn{5}{|l|}{ Apolipoproteins } \\
\hline Total apoB (g/L) & $1.12 \pm 0.22(111)$ & $\mathrm{I} .0 \mathrm{I} \pm 0.24(156) * * *$ & $0.89 \pm 0.23(155)$ & $0.86 \pm 0.19(205)$ \\
\hline VLDL-apoB (g/L) & $0.126 \pm 0.069(\mathrm{III})$ & $0.110 \pm 0.058(155)$ & $0.095 \pm 0.050(154)$ & $0.093 \pm 0.047(204)$ \\
\hline LDL-apoB (g/L) & $1.00 \pm 0.20(111)$ & $0.90 \pm 0.21(156) * * *$ & $0.80 \pm 0.20(155)$ & $0.77 \pm 0.18(204)$ \\
\hline apoAl (g/L) & $1.20 \pm 0.17(111)$ & $1.33 \pm 0.20(156) * * *$ & $1.18 \pm 0.16(155)$ & $1.23 \pm 0.17(205) * *$ \\
\hline \multicolumn{5}{|l|}{ Ratios } \\
\hline Plasma-C/HDL-C & $5.74 \pm 1.47(\mathrm{III})$ & $4.39 \pm 1.22(156) * * *$ & $4.51 \pm 1.33(155)$ & $3.98 \pm 1.06(204) * * *$ \\
\hline $\begin{array}{l}\text { VLDL-TG/ } \\
\text { VLDL-apoB } \\
(\mathrm{mmol} / \mathrm{g})\end{array}$ & $10.2 \pm 5.0(1 \mathrm{II})$ & $9.24 \pm 4.68(155)$ & $10.3 \pm 5.9(154)$ & $8.20 \pm 4.85(204) * * *$ \\
\hline $\begin{array}{l}\text { LDL-C/LDL-apoB } \\
(\mathrm{mmol} / \mathrm{g})\end{array}$ & $3.68 \pm 0.37(63)$ & $3.87 \pm 0.41(90) * *$ & $3.68 \pm 0.40(84)$ & $3.84 \pm 0.57(110) *$ \\
\hline $\begin{array}{l}\text { HDL-Cl } \\
\text { HDL-apoAl } \\
\text { (mmol/g) }\end{array}$ & $0.81 \pm 0.13(111)$ & $0.93 \pm 0.16(156) * * *$ & $0.87 \pm 0.15(155)$ & $0.94 \pm 0.16(204) * * *$ \\
\hline
\end{tabular}

publication of unexpected results from $\mathrm{HSL}^{-1-}$ mice studies and the discovery of an adipose triglyceride lipase. ${ }^{1}$ During a fasting state or moderate intensity exercise, the hormone-stimulated lipolytic pathway is activated as a result of a change in the balance between the stimulatory and inhibitory pathways of HSL activation. During moderate intensity exercise, lipid mobilisation is principally stimulated by an increase in catecholamine production, which stimulates lipolysis via $\beta$-adrenoceptors. ${ }^{6}$ The situation seems to be different, however, in the adipose tissue of obese subjects. Indeed, in obese subjects, basal lipolysis and HSL activity are significantly decreased in abdominal subcutaneous fat after 12 weeks of exercise training, despite an increase in the $\beta$-adrenergic component, reflecting greater catecholamine sensitivity. ${ }^{33}$ Finally, HSL expressed in skeletal muscle has been shown to be essential for intramuscular triacylglycerol hydrolysis during the first hour of moderate intensity exercise. ${ }^{7}$

Our results demonstrated the presence of significant gene (LIPE C-60G)-physical activity interactions on body fat and plasma lipid and lipoprotein levels, particularly in men. The presence of this interactive effect suggests that the 
Table 4. LIPE C-60G and LIPE C-60G-physical activity interactions on body fat, and plasma lipid and lipoprotein concentrations in men from the Quebec Family Study

\begin{tabular}{|c|c|c|c|c|c|c|c|}
\hline & \multirow{2}{*}{$\begin{array}{l}\text { C-60G } \\
p \text {-value }\end{array}$} & \multirow{2}{*}{$\begin{array}{l}\text { PA } \\
\text { p-value }\end{array}$} & \multicolumn{2}{|c|}{ C-60C by PA } & \multicolumn{2}{|c|}{ G-60 by PA } & \multirow{2}{*}{$\begin{array}{c}\text { Interaction } \\
\text { p-value }\end{array}$} \\
\hline & & & $\boldsymbol{\beta} \pm \mathrm{SE}$ & $p$-value & $\boldsymbol{\beta} \pm \mathrm{SE}$ & $p$-value & \\
\hline \multicolumn{8}{|l|}{ Body fat } \\
\hline BMI $\left(\mathrm{kg} / \mathrm{cm}^{2}\right)$ & 0.006 & 0.33 & $-0.2262 \pm 0.0888$ & 0.012 & $0.1118 \pm 0.0790$ & 0.16 & 0.006 \\
\hline Fat mass (kg) & 0.098 & 0.02 & $-0.3107 \pm 0.1184$ & 0.010 & $-0.0109 \pm 0.0766$ & 0.89 & 0.04 \\
\hline $\begin{array}{l}\text { Percentage body fat } \\
\text { (\%) }\end{array}$ & 0.69 & 0.04 & $-0.2322 \pm 0.0825$ & 0.006 & $-0.0332 \pm 0.0980$ & 0.74 & 0.13 \\
\hline $\begin{array}{l}\text { Abdominal visceral } \\
\text { fat }\left(\mathrm{cm}^{2}\right)\end{array}$ & 0.16 & 0.15 & $-0.0898 \pm 0.0749$ & 0.23 & $0.2496 \pm 0.0866$ & 0.005 & 0.005 \\
\hline $\begin{array}{l}\text { Abdominal } \\
\text { subcutaneous fat } \\
\left(\mathrm{cm}^{2}\right)\end{array}$ & 0.52 & 0.16 & $-0.1825 \pm 0.0752$ & 0.02 & $-0.0059 \pm 0.1169$ & 0.96 & 0.23 \\
\hline $\begin{array}{l}\text { Abdominal total fat } \\
\left(\mathrm{cm}^{2}\right)\end{array}$ & 0.30 & 0.20 & $-0.1612 \pm 0.0702$ & 0.02 & $-0.0332 \pm 0.1392$ & 0.81 & 0.43 \\
\hline \multicolumn{8}{|l|}{ Cholesterol } \\
\hline Plasma (mmol/L) & 0.27 & 0.68 & $-0.0506 \pm 0.0733$ & 0.49 & $0.1667 \pm 0.274 I$ & 0.54 & 0.45 \\
\hline $\mathrm{LDL}(\mathrm{mmol} / \mathrm{L})$ & 0.27 & 0.34 & $-0.0439 \pm 0.0710$ & 0.54 & $0.2820 \pm 0.2443$ & 0.25 & 0.21 \\
\hline HDL (mmol/L) & 0.84 & 0.16 & $0.0795 \pm 0.0658$ & 0.23 & $-0.4622 \pm 0.2595$ & 0.08 & 0.04 \\
\hline \multicolumn{8}{|l|}{ Triglyceride } \\
\hline Plasma (mmol/L) & 0.53 & 0.06 & $0.0443 \pm 0.0680$ & 0.52 & $0.3500 \pm 0.1964$ & 0.08 & 0.15 \\
\hline VLDL (mmol/L) & 0.63 & 0.18 & $0.0079 \pm 0.0668$ & 0.91 & $0.2546 \pm 0.1842$ & 0.17 & 0.15 \\
\hline \multicolumn{8}{|l|}{ Apolipoproteins } \\
\hline Total-apoB (g/L) & 0.52 & 0.27 & $-0.1335 \pm 0.0697$ & 0.06 & $0.3271 \pm 0.1635$ & 0.05 & 0.01 \\
\hline VLDL-apoB (g/L) & 0.71 & 0.37 & $-0.0428 \pm 0.0768$ & 0.59 & $0.2552 \pm 0.2217$ & 0.25 & 0.21 \\
\hline LDL-apoB (g/L) & 0.47 & 0.28 & $-0.1174 \pm 0.0718$ & 0.10 & $0.3154 \pm 0.1702$ & 0.07 & 0.02 \\
\hline apoAl (g/L) & 0.08 & 0.94 & $0.2276 \pm 0.0555$ & $<0.0001$ & $-0.2053 \pm 0.2858$ & 0.47 & 0.13 \\
\hline \multicolumn{8}{|l|}{ Ratios } \\
\hline Plasma-C/HDL-C & 0.72 & 0.11 & $-0.1757 \pm 0.0795$ & 0.03 & $0.5480 \pm 0.2188$ & 0.01 & 0.003 \\
\hline $\begin{array}{l}\text { VLDL-TG/ } \\
\text { VLDL-apoB (mmol/g) }\end{array}$ & 0.87 & 0.80 & $0.0187 \pm 0.0654$ & 0.78 & $0.0446 \pm 0.2425$ & 0.85 & 0.92 \\
\hline $\begin{array}{l}\text { LDL-C/LDL-apoB } \\
(\mathrm{mmol} / \mathrm{g})\end{array}$ & 0.38 & $<0.0001$ & $-0.0070 \pm 0.0774$ & 0.93 & $-1.0577 \pm 0.1644$ & $<0.0001$ & $<0.0001$ \\
\hline $\begin{array}{l}\text { HDL-C/HDL-apoAI } \\
(\mathrm{mmol} / \mathrm{g})\end{array}$ & 0.28 & $<0.0001$ & $-0.0834 \pm 0.0655$ & 0.21 & $-0.5382 \pm 0.1381$ & 0.0002 & 0.004 \\
\hline
\end{tabular}

Values represent percentage of variance and $p$-values for each of the effects included in the model. See Materials and methods section for details. Significant results are highlighted in bold type.

Abbreviations: apo, apolipoprotein; BMI, body mass index; C, cholesterol; HDL-C, high-density lipoprotein cholesterol; LDL-C, low-density lipoprotein cholesterol; SE, standard error; TG, triglyceride; VLDL, very-low-density lipoprotein 
Table 5. LIPE C-60G and LIPE C-60G-physical activity interactions on body fat, and plasma lipid and lipoprotein concentrations in women from the Quebec Family Study

\begin{tabular}{ccccccc} 
C-60G & PA & \multicolumn{2}{c}{ C-60 by PA } & G-60 by PA & Interaction \\
p-value & $p$-value & $\beta \pm$ SE & $p$-value & $\beta \pm$ SE & $\begin{array}{c}p \\
\text { value }\end{array}$ & $p$-value
\end{tabular}

\section{Body fat}

\begin{tabular}{|c|c|c|c|c|c|c|c|}
\hline $\mathrm{BMI}\left(\mathrm{kg} / \mathrm{cm}^{2}\right)$ & 0.88 & 0.02 & $-0.0526 \pm 0.0640$ & 0.41 & $-0.3013 \pm 0.1333$ & 0.02 & 0.09 \\
\hline Fat mass $(\mathrm{kg})$ & 0.60 & 0.04 & $-0.0883 \pm 0.0665$ & 0.19 & $-0.1864 \pm 0.1136$ & 0.10 & 0.46 \\
\hline Percentage body fat (\%) & 0.41 & 0.01 & $-0.11117 \pm 0.0574$ & 0.05 & $-0.2261 \pm 0.1178$ & 0.06 & 0.38 \\
\hline $\begin{array}{l}\text { Abdominal visceral fat } \\
\left(\mathrm{cm}^{2}\right)\end{array}$ & 0.26 & 0.65 & $-0.0057 \pm 0.0647$ & 0.93 & $0.0591 \pm 0.1315$ & 0.65 & 0.72 \\
\hline $\begin{array}{l}\text { Abdominal } \\
\text { subcutaneous fat }\left(\mathrm{cm}^{2}\right)\end{array}$ & 0.67 & 0.002 & $-0.0925 \pm 0.0607$ & 0.13 & $-0.4103 \pm 0.1457$ & 0.006 & 0.05 \\
\hline $\begin{array}{l}\text { Abdominal total fat } \\
\left(\mathrm{cm}^{2}\right)\end{array}$ & 0.59 & 0.003 & $-0.0895 \pm 0.0579$ & 0.12 & $-0.4232 \pm 0.1567$ & 0.008 & 0.05 \\
\hline
\end{tabular}

\section{Cholesterol}

\begin{tabular}{|c|c|c|c|c|c|c|c|}
\hline Plasma (mmol/L) & 0.48 & 0.40 & $-0.0847 \pm 0.0807$ & 0.30 & $-0.0624 \pm 0.1529$ & 0.68 & 0.90 \\
\hline LDL (mmol/L) & 0.45 & 0.60 & $-0.0380 \pm 0.0777$ & 0.63 & $-0.0484 \pm 0.1436$ & 0.74 & 0.95 \\
\hline $\mathrm{HDL}$ (mmol/L) & 0.66 & 0.17 & $-0.0548 \pm 0.0608$ & 0.37 & $-0.1158 \pm 0.1147$ & 0.31 & 0.65 \\
\hline \multicolumn{8}{|l|}{ Triglyceride } \\
\hline Plasma (mmol/L) & 0.87 & 0.95 & $-0.0329 \pm 0.0566$ & 0.56 & $0.0411 \pm 0.1313$ & 0.76 & 0.62 \\
\hline VLDL (mmol/L) & 0.95 & 0.56 & $-0.0453 \pm 0.0592$ & 0.45 & $-0.0538 \pm 0.1602$ & 0.74 & 0.96 \\
\hline \multicolumn{8}{|l|}{ Apolipoproteins } \\
\hline Total-apoB (g/L) & 0.80 & 0.41 & $-0.0620 \pm 0.0641$ & 0.33 & $-0.0760 \pm 0.1572$ & 0.63 & 0.94 \\
\hline VLDL-apoB (g/L) & 0.97 & 0.87 & $-0.0432 \pm 0.0525$ & 0.41 & $0.0153 \pm 0.1603$ & 0.92 & 0.73 \\
\hline LDL-apoB (g/L) & 0.81 & 0.43 & $-0.054 I \pm 0.0644$ & 0.40 & $-0.0708 \pm 0.1464$ & 0.63 & 0.92 \\
\hline apoAI (g/L) & 0.79 & 0.82 & $-0.0252 \pm 0.0641$ & 0.69 & $-0.0046 \pm 0.1233$ & 0.97 & 0.89 \\
\hline \multicolumn{8}{|l|}{ Ratios } \\
\hline Plasma-C/HDL-C & 0.96 & 0.99 & $-0.0362 \pm 0.0682$ & 0.84 & $-0.0137 \pm 0.1601$ & 0.93 & 0.88 \\
\hline $\begin{array}{l}\text { VLDL-TG/VLDL-apoB } \\
(\mathrm{mmol} / \mathrm{g})\end{array}$ & 0.22 & 0.14 & $-0.0609 \pm 0.0634$ & 0.34 & $-0.2242 \pm 0.1781$ & 0.21 & 0.38 \\
\hline $\begin{array}{l}\text { LDL-C/LDL-apoB } \\
(\mathrm{mmol} / \mathrm{g})\end{array}$ & 0.39 & 0.74 & $-0.0026 \pm 0.0908$ & 0.98 & $-0.0538 \pm 0.1370$ & 0.70 & 0.75 \\
\hline $\begin{array}{l}\text { HDL-C/HDL-apoAI } \\
(\mathrm{mmol} / \mathrm{g})\end{array}$ & 0.43 & 0.19 & $-0.0590 \pm 0.0599$ & 0.33 & $-0.1330 \pm 0.1365$ & 0.33 & 0.63 \\
\hline
\end{tabular}

Values are percentage of variance and p-values for each effect included in the model. See Materials and methods section for details. Significant results are highlighted in bold type. Abbreviations: apo, apolipoprotein; BMI, body mass index; C, cholesterol; HDL-C, high-density lipoprotein cholesterol; LDL-C, low-density lipoprotein cholesterol; SE, standard error; TG, triglyceride; VLDL, very-low-density lipoprotein 
relationship between physical activity and body fat, as well as plasma lipids and lipoproteins, varies according to LIPE C-60G genotype. Indeed, male carriers of the LIPE G-60 allele did not appear to benefit as much from physical activity for body fat (BMI) and plasma lipid cardiovascular risk factors such as the plasma cholesterol/HDL-C ratio (Table 4 and Figure 1). One explanation for this is that, compared with male non-carriers of the LIPE G-60 allele who have a lower BMI in the high physically active group than in the low physically active group (physical activity contributes to weight loss by stimulating lipid mobilisation), male carriers of the LIPE G-60 allele (an allele that confers a lower transcriptional activity ${ }^{12,14}$ ) exhibit a higher BMI (lower lipid mobilisation) in the high physically active group than in the low physically active group. Thus, a lipid mobilisation defect in physically active carrier men contributes to a higher BMI, associated with lower HDL-C production and leading to a higher plasma cholesterol/HDL-C ratio. This is what we observed with the significant LIPE C-60G-physical activity interaction term on plasma cholesterol/HDL-C ratio $(p=0.003)$ (Figure 1), suggesting that, in men, it may be important to take this interaction effect into account for future LIPE C-60G association studies.

Women also exhibited significant gene (LIPE C-60G)-physical activity interactions for body fat phenotypes. By contrast with men, however, only female carriers of the LIPE G-60 allele appear to benefit from physical activity for BMI and abdominal subcutaneous fat (Figure 1). Indeed, female carriers of the LIPE G-60 allele in the high physical activity group exhibited a significantly lower BMI $(p=0.008)$ and abdominal subcutaneous fat area $(p=0.007)$ than carriers in the low physical activity group. These relationships between physical activity and body fat according to LIPE C-60G genotype were not affected by menopause (data not shown). We have previously shown that sedentary Caucasian women carrying the LIPE G-60 allele exhibited a lower percentage of fat and sum of eight skinfolds. ${ }^{13}$ Thus, in the present study and in previous studies, we have observed that carriers of the LIPE G-60 allele exhibited reduced body fat in the subcutaneous compartment, ${ }^{13}$ which is lowered in physically active women.

It has been suggested that the DNA sequence located between nucleotides -86 and -57 is necessary for the expression of HSL. ${ }^{34}$ Moreover, the C-60G polymorphism has been shown to affect the expression of HSL in in vitro studies that showed that the genomic sequence (-86 to-85 bp upstream of the transcription start site) with the G-60 nucleotide inserted into a pGL3-Enhancer vector resulted in a 40 per cent lower luciferase activity compared with the wide-type $-60 \mathrm{C}$ construct. ${ }^{12}$ Unexpected results were observed in studies using hsl knockout mice, since these animals exhibited reduced adipose tissue ${ }^{35}$ and mild hyperglycaemia ${ }^{36}$ compared with wild-type mice. All together, these results suggest that a metabolic compensatory effect may occur in the absence of, or with reduced, HSL expression. From our results, we suspect that only female carriers of the $-60 \mathrm{G}$ allele are probably able to counteract the lower HSL expression level, through metabolic compensation. Indeed, mice deficient in $h s l$ in adipose tissue exhibited many metabolic adaptations, ${ }^{35}$ including lower fatty acid de novo synthesis, which may explain the observed lower body fat in Caucasian women from the HERITAGE Family Study carriers of the LIPE G-60 allele. As physical activity promotes the mobilisation of fatty acids stored in adipose tissue, it is possible that such activity reinforces the metabolic compensation occurring when HSL expression level is low, resulting in a lower BMI and abdominal subcutaneous fat area in physically active female carriers of the LIPE G-60 allele. No effects were observed for plasma lipid and lipoprotein concentrations in women.

Since this study is the first to demonstrate a gene-physical activity interaction on body fat and plasma lipid and lipoprotein concentrations using the LIPE C-60G polymorphism, these results need to be replicated. Although multiple statistical tests have been performed, thus highlighting the chance for obtaining spurious significant association genephysical activity interaction with BMI $(p=0.006)$, fat mass $(p=0.04)$, abdominal visceral fat $(p=0.005)$ and plasma cholesterol/HDL-C ratio $(p=0.003)$ 
in men, and with abdominal subcutaneous fat $(p=$ $0.005)$ and abdominal total fat $(p=0.05)$ in women are strong enough to be considered as significant. Finally, the physical activity score used in the present study has been demonstrated in other studies to be characterised by good reproducibility and to be well correlated with parameters of physical fitness. ${ }^{37}$

In summary, this study tested for LIPE G-60Cphysical activity interactions on body fat and plasma lipid and lipoprotein levels in the QFS cohort. In men, significant LIPE C-60G-physical activity interactions were observed for BMI, abdominal visceral fat area and plasma cholesterol/ HDL-C ratio, whereas in women an interaction was observed only for abdominal subcutaneous fat area. These observations emphasise the importance of taking into account gene-physical activity interactions in association studies involving candidate genes for obesity and obesity-related traits. It would be useful to verify these observational data in a controlled exercise intervention study.

\section{Acknowledgments}

Christophe Garenc has a scholarship from the Fonds de la recherche en santé du Québec. Claude Bouchard is partially supported by the George A. Bray Chair in Nutrition. Thanks are expressed to Dr G. Theriault and to G. Fournier, L. Allard, M. Chagnon and C. Leblanc for their contributions to the recruitment and data collection of the QFS, to Manon Bélair for her technical assistance and to Diane Drolet for secretarial support. This study was supported by a New Emerging Team grant (NET) from the Canadian Institute of Health Research (OHN-63276).

\section{References}

1. Zechner, R., Strauss, J.G., Haemmerle, G., Lass, A. and Zimmermann, R. (2005), 'Lipolysis: Pathway under construction', Curr. Opin. Lipidol. Vol. 6, pp. 333-340.

2. Carey, G.B. (1998), 'Mechanisms regulating adipocyte lipolysis', $A d v$. Exp. Med. Biol. Vol. 441, pp. 157-170.

3. Holm, C., Österlund, T., Laurell, H. and Contreras, J.A. (2000), 'Molecular mechanisms regulating hormone-sensitive lipase and lipolysis', Annu. Rev. Nutr. Vol. 20, pp. 365-393.

4. Langin, D., Holm, C. and Lafontan, M. (1996), 'Adipocyte hormonesensitive lipase: A major regulator of lipid metabolism'. Proc. Nutr. Soc Vol. 55(1B), pp. 93-109.

5. Large, V. and Arner, P. (1998), 'Regulation of lipolysis in humans. Pathophysiological modulation in obesity, diabetes, and hyperlipidaemia', Diabetes Metab. Vol. 24, pp. 409-418.
6. Arner, P. (1995), 'Impact of exercise on adipose tissue metabolism in humans', Int. J. Obes. Relat. Metab. Disord. Vol. 19 (Suppl. 4), pp. S18-S21.

7. Watt, M.J. and Spriet, L.L. (2004), 'Regulation and role of hormonesensitive lipase activity in human skeletal muscle', Proc. Nutr. Soc. Vol. 63, pp. 315-322.

8. Levitt, R.C., Liu, Z., Nouri, N., Meyers, D.A., Brandriff, B. and Mohrenweiser, H.M. (1995), 'Mapping of the gene for hormone sensitive lipase (LIPE) to chromosome 19q13.1-- > q13.2', Cytogenet. Cell Genet. Vol. 69, pp. 211-214.

9. Bossé, Y., Chagnon, Y.C., Després, J.P. et al. (2004), 'Genome-wide linkage scan reveals multiple susceptibility loci influencing lipid and lipoprotein levels in the Quebec Family Study', J. Lipid Res. Vol. 45, pp. 419-426.

10. Feitosa, M.F., Rice, T., North, K.E. et al. (2006), 'Pleiotropic QTL on chromosome 19q13 for triglycerides and adiposity: The HERITAGE Family Study', Atherosclerosis Vol. 185, pp. 426-432.

11. Elbein, S.C. and Hasstedt, S.J. (2002), 'Quantitative trait linkage analysis of lipid-related traits in familial type 2 diabetes: Evidence for linkage of triglyceride levels to chromosome 19q', Diabetes Vol. 51, pp. $528-535$.

12. Talmud, P.J., Palmen, J. and Walker, M. (1998), 'Identification of genetic variation in the human hormone-sensitive lipase gene and $5^{\prime}$ sequences: Homology of $5^{\prime}$ sequences with mouse promoter and identification of potential regulatory elements', Biochem. Biophys. Res. Commun. Vol. 252, pp. 661-668.

13. Garenc, C., Pérusse, L., Chagnon, Y.C. et al. (2002), 'The hormonesensitive lipase gene and body composition: The HERITAGE Family Study', Int. J. Obes. Relat. Metab. Disord. Vol. 26, pp. 220-227.

14. Carlsson, E., Johansson, L.E., Strom, K. et al. (2006), 'The hormonesensitive lipase C-60G promoter polymorphism is associated with increased waist circumference in normal-weight subjects', Int. J. Obes. Vol. 30, pp. 1442-1448.

15. Talmud, P.J., Palmen, J., Luan, J. et al. (2001), 'Variation in the promoter of the human hormone sensitive lipase gene shows gender specific effects on insulin and lipid levels: Results from the Ely study', Biochim. Biophys. Acta Vol. 1537, pp. 239-244.

16. Qi, L., Shen, H., Larson, I., Barnard, J., Schaefer, E. and Ordovas, J. (2004), 'Genetic variation at the hormone sensitive lipase: genderspecific association with plasma lipid and glucose concentrations', Clin. Genet. Vol. 65, pp. 93-100.

17. Talmud, P.J., Palmen, J., Nicaud, V. and Tiret, L. (2002), 'Association of the hormone sensitive lipase $-60 \mathrm{C}>\mathrm{G}$ variant with fasting insulin levels in healthy young men', Nutr. Metab. Cardiovasc. Dis. Vol. 12, pp. 173-177.

18. Kelley, G.A., Kelley, K.S. and Tran, Z.V. (2004), 'Walking, lipids, and lipoproteins: A meta-analysis of randomized controlled trials', Prev. Med. Vol. 38, pp. 651-661.

19. Rankinen, T., Bray, M.S., Hagberg, J.M. et al. (2006), 'The human gene map for performance and health-related fitness phenotypes: The 2005 update', Med. Sci. Sports Exercise Vol. 38, pp. 1863-1888.

20. Bouchard, C. (1996), 'Genetic epidemiology, association and sib-pair linkage: Results from the Québec Family Study', in: Bray, G.A. and Ryan, D.H. (eds), Molecular and Genetic Aspects of Obesity. Louisiana State University Press, Baton Rouge, LA, pp. 470-481.

21. Behnke, A. and Wilmore, W. (1974), Evaluation and regulation of body build and composition, Prentice-Hall, Englewood Cliffs, NJ, USA.

22. Siri, W.E. (1956), 'The gross composition of the body', Adv. Biol. Med. Phys. Vol. 4, pp. 239-280.

23. Pérusse, L., Rice, T., Chagnon, Y.C. et al. (2001), 'A genome-wide scan for abdominal fat assessed by computed tomography in the Quebec Family Study', Diabetes Vol. 50, pp. 614-621.

24. Leclerc, S., Bouchard, C., Talbot, J., Gauvin, R. and Allard, C. (1983), 'Association between serum high-density lipoprotein cholesterol and body composition in adult men', Int. J. Obes. Vol. 7, pp. 555-561.

25. Allain, C.C., Poon, L.S., Chan, C.S., Richmond, W. and Fu, P.C. (1974), 'Enzymatic determination of total serum cholesterol', Clin. Chem. Vol. 20, pp. 470-475. 
26. Fossati, P. and Prencipe, L. (1982), 'Serum triglycerides determined colorimetrically with an enzyme that produces hydrogen peroxide', Clin. Chem. Vol. 28, pp. 2077-2080.

27. Burstein, M. and Samille, J. (1960), 'Sur un dosage rapide du cholesterol lié aux $\beta$-lipoprotéines du sérum', Clin. Chim. Acta Vol. 5, pp. 609-610.

28. Laurell, C.B. (1960), 'Quantitative estimation of proteins by electropheresis in agarose gel containing antibodies', Anal. BioChem. Vol. 5, pp. $609-610$.

29. Moorjani, S., Dupont, A., Labrie, F. et al. (1987), 'Increase in plasma high-density lipoprotein concentration following complete androgen blockage in men with prostatic carcinoma', Metabolism Vol. 36, pp. $244-250$.

30. Bouchard, C., Tremblay, A., Leblanc, C., Lortie, G., Savard, R. and Theriault, G. (1983), 'A method to assess energy expenditure in children and adults', Am. J. Clin. Nutr. Vol. 37, pp. 461-467.

31. Simonen, R.L., Perusse, L., Rankinen, T., Rice, T., Rao, D.C. and Bouchard, C. (2002), 'Familial aggregation of physical activity levels in the Quebec Family Study. Medicine and science in sports and exercise', Vol. 34, pp. 1137-1142.
32. SAS. (1996), Statistical Analysis System (6.12 ed). SAS Institute Inc., Cary, $\mathrm{NC}$

33. De Glisezinski, I., Crampes, F., Harant, I. et al. (1998), 'Endurance training changes in lipolytic responsiveness of obese adipose tissue', Am. J. Physiol. Vol. 275, pp. E951-E956.

34. Grober, J., Laurell, H., Blaise, R. et al. (1997), 'Characterization of the promoter of human adipocyte hormone-sensitive lipase', Biochem. J. Vol. 328 , pp. $453-461$.

35. Zimmermann, R., Haemmerle, G., Wagner, E.M., Strauss, J.G., Kratky, D. and Zechner, R. (2003), 'Decreased fatty acid esterification compensates for the reduced lipolytic activity in hormone-sensitive lipase-deficient white adipose tissue', J. Lipid Res. Vol. 44, pp. 2089-2099.

36. Mulder, H., Sorhede-Winzell, M., Contreras, J.A. et al. (2003), 'Hormone-sensitive lipase null mice exhibit signs of impaired insulin sensitivity whereas insulin secretion is intact. J. Biol. Chem. Vol. 278, pp. $36380-36388$

37. Robert, H., Casillas, J.M., Iskandar, M. et al. (2004), 'The Dijon Physical Activity Score: reproducibility and correlation with exercise testing in healthy elderly subjects', Ann. Readapt. Med. Phys. Vol. 47, pp. 546-554. 